\title{
The Impacts of COVID-19 on Early Childhood Education: Capturing the Unique Challenges Associated with Remote Teaching and Learning in $\mathrm{K}-2$
}

\author{
Kristy Timmons $^{1}$ (D) $\cdot$ Amanda Cooper $^{1} \cdot$ Emma Bozek $^{1} \cdot$ Heather Braund $^{1}$
}

Accepted: 30 April 2021 / Published online: 14 May 2021

(C) The Author(s), under exclusive licence to Springer Nature B.V. 2021

\begin{abstract}
Due to the COVID-19 pandemic, schools across North America closed to in person learning in March 2020. Since then, it has become increasingly clear that physical distancing will need to be prolonged in the 2020/2021 school year and possibly resumed in the future. In response, education ministries shifted teaching and learning online. Research is urgently needed to mitigate the effects of COVID-19 on teaching and learning, particularly in the foundational early primary years. This research directly responds to this concern by examining the unique challenges associated with remote teaching and learning in early primary contexts. Given that learning in kindergarten and early primary grades is largely play- and inquiry- based, there is a particular need to investigate the impacts of this move for teachers, parents, and children in K-2. As such, the purpose of this research is twofold: (1) to capture the unique challenges and unanticipated successes associated with remote teaching and learning, and (2) to utilize findings to provide recommendations for remote learning as well as strategies for supporting in-person learning in the COVID-19 era (and post COVID-19 era). Data collection included 45-min semi-structured interviews with K-2 teachers $(n=25)$ and parents $(n=11)$. All participants were from Ontario Canada. Data were collected from April-June 2020. The sample size was chosen to ensure saturation while uncovering a variety of perspectives. Data were analyzed in NVivo using an emergent thematic approach (Patton, 2016). The emergent thematic approach to analysis revealed five themes: equity considerations, synchronous versus asynchronous teaching and learning, social and emotional effects on students, academic impacts, and effects on parents/families.
\end{abstract}

Keywords COVID-19 $\cdot$ School closures $\cdot$ Early childhood education $\cdot$ Remote teaching and learning

\section{Introduction}

The World Health Organization declared COVID-19 a pandemic on March 12th, 2020 (Viner, 2020); upon this declaration, nations world-wide began instituting temporary school closures (Wang et al., 2020) as a part of community-based public health measures (Wilder-Smith \& Freedmann, 2020).

Kristy Timmons

kristy.timmons@queensu.ca

Amanda Cooper

amanda.cooper@queensu.ca

Emma Bozek

17elb1@queensu.ca

Heather Braund

hlab@queensu.ca

1 Faculty of Education, Queen's University, Kingston, Canada
Among other public health measures, such as mandated mask wearing in public spaces and mandatory social distancing (Wang et al., 2020), these measures were instituted in an attempt to slow the spread of the COVID-19 pandemic. The peak of school-closures world-wide was in April 2020, at which point 199 countries had school closures in place (World Food Program, 2020).

School closure protocols varied across Canada (where the current research was conducted) under the guidance of provincial/territorial health authorities (Alphonso, 2020; Government of Canada, 2020). Individual provinces and territories adopted remote teaching and learning protocols as the pandemic progressed over the spring of 2020. The Ontario Ministry of Education mandated that all teaching be moved to remote learning in March of 2020 (Government of Ontario, 2020a), calling this the Learn at Home Initiative (Government of Ontario, 2020b). The Learn at Home Initiative extended indefinitely over the spring of 
2020 (Government of Ontario, 2020c, 2020d, 2020e, 2020f). Given that learning in the early primary grades is largely play- and inquiry- based and focuses on social, emotional, and cognitive aspects of learning, policy makers, teachers, and parents were particularly concerned about the short- and long-term impact of remote teaching on learning in the early years. As such, there was a need to investigate the impacts of this move for teachers, parents, and children in Ontario.

\section{Understanding the Unique Impacts of Remote Teaching Initiatives in Early Primary Contexts}

Due to the complex and multifaced nature of early primary education, the shift to remote teaching and learning proved to be quite difficult for teachers, parents, and students (Timmons et al., 2020; Yamamura \& Tsustsui, 2021). Ontario's Pedagogy for the Early Years identifies four conditions required for children in their learning: (1) belonging-which involves connecting with others and forming relationships, (2) well-being- which focuses on the physical and mental health of students, (3) engagement-which involves creating opportunities for students to explore with their natural curiosity, and (4) expression- which focuses on providing opportunities for students to communicate in a variety of forms (Ontario Ministry of Education, 2014b). Imperative to learning in the early years, these four foundational conditions "of early years programs ensures optimal learning and healthy development" (Ontario Ministry of Education, 2014 b, p.8). Over the past decade, teachers have worked to ensure their practices embrace these four learning conditions. The shift to remote teaching and learning has meant a complete re-thinking of the delivery of early years programs, whereby teachers needed to examine how they would meet the four conditions for learning in a remote context.

In Ontario, early primary programs are largely taught through play- and inquiry-based approaches. These play- and inquiry-based activities require teachers to probe learning and curiosity as it occurs. The role of teachers in this process cannot be overstated, as they "depend on their nuanced understanding of the many ways in which children learn and develop and how children's grasp of concepts is revealed during play" (Ontario Ministry of Education, 2016, p.19; Trawick-Smith \& Dziurgot, 2010). In this capacity, teachers work to co-facilitate and extend learning.

The early primary grades are important for the acquisition of foundational language, literacy, and math skills (Ontario Ministry of Education, 2016; Piasta, 2016; Purpura et al., 2011). Language and literacy skills develop as children learn to communicate through a variety of interactions, both verbally and non-verbally (Ontario Ministry of Education, 2016). To ensure literacy interactions are meaningful, teachers in the early primary grades are continuously assessing (both formally and informally) literacy and language skills of individual students to ensure that teaching is tailored to individual learning goals. Similar to literacy learning, mathematics skills in the early primary grades are often fostered through teacher guided play-based activities, where students have the opportunity to develop numeracy skills, create patterns, sort items, and estimate (Ginsberg, 2006; Hunting, 2010) among other things. For rich learning to take place, however, purposeful interactions between teacher and student must take place (De Vries et al. 2010; Ginsberg et al., 2008) wherein the teachers can differentiate instruction to individual student abilities and interests. This allows teachers to support students in consolidating and extending their learning to relevant contexts. Thus, framed within play-based learning, quality language, literacy, and mathematics instruction requires teachers to thoughtfully engage with individual students and to meet students where they are. This becomes increasingly challenging to do when teaching and learning is shifted online. As such, teachers were challenged with how to continue to offer a play-based inquiry program that meets curriculum expectations within a remote teaching context. With the onset of the Learn at Home Initiative, teacher roles shifted to unknown territory. Although their duties remain, teacher capacity to facilitate and consolidate student learning has been reduced. Teachers now require more support from families to support the academic and social learning of students.

According to Ontario's Pedagogy for the Early Years “the web of family and community is the child's anchor for early development" (Ontario Ministry of Education, 2014a, p.3). The Learn at Home Initiative required parents to take an active role in their children's learning unlike ever before. Moving instruction online means that K-2 students will require a profound amount of support in accessing the learning materials, as most will not have the skills or experience required to navigate technology and software to complete assigned activities independently. As such, remote teaching and learning requires that families assist their children with not only accessing the learning materials shared remotely with children but also with the delivering of instruction (Pramling Samuelsson et al., 2020). This requires that parents understand the learning expectations for all activities. Despite considerable involvement of families in the learning of their children prior to the COVID-19 pandemic, the additional requirement for families to take on the role of the teacher in delivering instruction proved to be challenging for parents (Timmons et al., 2020).

\section{Setting the Context: Implementation of Remote Teaching and Learning}

The transition to remote teaching and learning has varied within and across countries, ministries, boards of education, schools, and at the individual classroom and 
teacher level (Fahrurrozi et al. 2021; Sangeet \& Tandon, 2020); without precedent to consider, a lack of policy left much discrepancy among teachers regarding delivery. The Ontario Government outlined the minimum expectations for student worktime in a given week based on the learning materials and work assigned by teachers. For early primary students, these expectations included five hours of schoolwork per student per week, with an emphasis on math and literacy learning (Ontario Ministry of Education, 2020g).

The Learn at Home remote teaching initiative requires teachers and families to have access to internet, educational resources, and appropriate software (Van Nuland et al. 2020), in order to engage in the learning process and enhance capacity to support children in a remote context (Garbe et al. 2020). Although stated as requirements for success, access to reliable internet proved to be a barrier for at least $12 \%$ of Ontario households (Van Nuland et al. 2020). Moving forward, equitable access to learning for all students must be a priority as teaching and learning is shifted online (Timmons et al., 2020).

The delivery of remote teaching and learning most often includes both synchronous and asynchronous aspects of learning (Mladenova et al., 2020; Moorhouse \& Beaumont, 2020; Ross \& DiSalvo, 2020; Schwartz, 2020; Yi \& Yang, 2020). Sometimes mandated by individual schoolboards, the form of delivery varies accordingly, however, it is also dependent on the teachers' capacity to deliver either synchronous or asynchronous programming (Miruna, 2020). In synchronous delivery, teachers and students meet in real time. Asynchronous learning allows more flexibility as students can complete learning activities on their own schedule (within parameters set out by the teacher). Typical methods of asynchronous learning include prerecorded video or audio content, lesson plans/modules, links to external videos, and discussion boards. Unsurprisingly, the shift from in-person teaching and learning to synchronous and asynchronous delivery of instruction came with great concern for potential negative academic and social effects on students. There were unique concerns for the early years, given that learning in the early primary grades focuses on developing early literacy, language, and mathematic skills (Ontario, 2016) that are foundational for lasting academic success (Pinto et al. 2016). These concerns were exacerbated given that the frequency of instruction was greatly reduced with the move to remote instruction. The halt of in-person learning in which students transitioned from 5-6 h of school a day (Government of Canada, 2017) to $5 \mathrm{~h}$ a week resulted in concerns for the quality of early primary education (Timmons et al., 2020). A reduction in quality related to changes in the delivery and frequency of instruction requires an examination of the short- and long-term academic and social implications of remote teaching and learning.
In addition to academic skills, the early primary grades are essential for the development of social skills, as children learn to negotiate and collaborate with peers (Blair et al., 2018). The Ontario kindergarten curriculum highlights that "learning and development take place in the context of social relationships" (2016, p. 108), as children begin to understand the world based on interactions with their peers, their family, their community, and their teachers. Moving to remote teaching and learning contexts means that if social interactions are happening, they are only occurring through online video meetings, where it is difficult and arguably impossible to develop the pro-social skills for which a play-based early learning environment naturally allows. As the current context raises concerns about the uncertainty regarding the safety of in-person learning, and the increasing possibility that social distancing will need to be prolonged, or possibly resumed, in the future (Viner et al., 2021), it is important to understand how teachers moved their instruction online and how best to support teachers and parents with these efforts if remote learning continues in the future. This research is part of a larger Ontario study that sought to examine the implementation and impact of remote teaching and learning initiatives in early primary (kindergarten, grade 1 , and grade 2) and secondary school (grade 9-12) contexts in Ontario. The research presented in this article directly responds to the education challenges faced in the early primary education context.

\section{Methodology}

This study was approved by the Queen's University Graduate Research and Ethics Board (GREB). Participants provided informed consent with knowledge that their participation was voluntary, and the personal information would remain confidential to the research team. A convenience purposive sampling technique was used to recruit teacher and parent participants. Participation was advertised via social media (Twitter, Facebook) and participants were selected if they were a) a qualitied teacher or early childhood educator currently working in grades $\mathrm{K}-2$, or b) a parent of a child in grades K-2. Recruiting through social media platforms allowed for a broad sampling of educators and families across Ontario. These procedures improve population integrity in recruitment. The sample size was chosen to ensure saturation (large enough sample to sufficiently address the research questions) while uncovering a variety of perspectives. Qualitative methods were chosen because of their ability to provide flexibility and explore more deeply the emerging trends of remote teaching and learning.

This research utilized semi-structured interviews (approximately $45 \mathrm{~min}$ ) to capture the perspectives of early primary teachers $(n=25)$ and parents $(n=11)$. Semi-structured 
interviews were conducted via Microsoft Teams or a password protected Zoom meeting using a common interview protocol (See Appendix A). The semi-structured interview questions were developed with the goal of addressing the research questions while also ensuring that a range of perspectives and experiences could be captured from educators and parents. Next, the interview questions were reviewed by the research team and colleagues working in the early primary field. Finally, the interview protocol was reviewed by GREB. All interviews were conducted by the PI.

\section{Teacher Interview}

Interviews with teachers focused on the following topics/ questions:

- School/school board resources and supports

- Perspectives on impact (on students, parents, and teachers- short- and long-term)

- Planning: How are teachers planning for remote learning? How is this different from the ways in which teachers planned previously?

- Teaching and Learning: Describe what remote learning looks like. Weekly schedule.

- What does play and play-based learning look like in remote instruction?

- Assessment: How do you assess learning that takes place remotely? Assessment examples.

- Transition back to in-person learning

- Recommendations for improvement and support (shortand long-term)

\section{Parent Interview}

Interviews with parents focused on the following topics/ questions:

- Described what remote learning looks like for their child (week plan)

- Engagement

- Impact (short- and long-term/ successes and challenges)

- Supports they need now and what they will need when child goes back to in person learning

- Their role in the learn at home initiative

- Parenting (best/hardest things)

- Transition back to in-person learning (and what the fall will look like)

- Recommendations for improvement and support (shortand long-term)

As stated previously, this research comes from a larger research study that sought to examine the implementation and impact of remote teaching and learning initiatives in early primary and secondary school contexts. One PI led the early primary research team, and the second PI lead the secondary school research team. Although only the data from the early primary research is reported in this paper, it is important to acknowledge the larger study in order to best capture the coding procedures.

In an effort to increase dependability and trustworthiness, the following sections describe the detailed coding process (Tobin \& Begley, 2004). Once the interviews were transcribed verbatim, the two PIs (early primary and secondary context) met to develop a data-driven codebook. Once the first draft of the codebook was developed, the coding structure was shared with both research teams. A 1.5-h training meeting was held to review the initial data-driven codebook developed through an initial inductive coding of the interviews. A second, 2-h meeting was set with the two research assistants from the early primary team to further discuss and review the data-driven codebook. Questions and concerns regarding the coding structure were discussed and minor key-word changes were made to more accurately address the interview questions. Following the training meetings, the two research assistants from the early primary team individually coded 6 interviews ( 3 teacher and 3 parent interviews) to ensure inter-rater reliability. A third research training meeting $(1.5 \mathrm{~h})$ was scheduled to review the coding procedures and data-driven codes, and additional changes were made to the codebook. Inter-rater reliability of $98 \%$ was achieved. Reliability was calculated by comparing agreements divided by agreements and disagreements. Where there were disagreements, the research team discussed the meaning of each code in context of the participant responses to ensure consistency. This procedure is consistent with reliability procedures employed in previous research (Heagle et al., 2017; Timmons, 2018; Timmons, 2019; Timmons et al., 2020).

After completing the data-driven codebook, the teacher and parent data were thematically analyzed (Patton, 2002; Thomas, 2006). For this process, similar codes were grouped together into categories. The research team then examined the data within the categories to identity broader patterns known as themes. From these themes, narrative descriptions of themes were generated (see Table 1). Thomas (2006) discusses the purposes of an inductive approach as threefold: (1) to condense raw text data into a summary format, (2) to establish clear links between research objectives and findings derived from the raw data while ensuring transparency, and (3) to develop a framework of the underlying structure as evident in the raw data. This approach provides a systematic procedure for analyzing qualitative data that produces reliable and valid findings (Thomas, 2006) and provides the structure and simplicity required in interpreting teacher and parent perspectives. 
Table 1 Summary of themes

\begin{tabular}{|c|c|c|}
\hline Theme & Description & Frequency \\
\hline 1. Equity considerations & $\begin{array}{l}\text { Discussions relate to accessing technology, missing essential } \\
\text { resources, training to use technology, accommodating for lack of } \\
\text { access, and challenges at home }\end{array}$ & $\begin{array}{l}23 \text { for teachers } \\
9 \text { for parents }\end{array}$ \\
\hline 2. Synchronous vs. asynchronous teaching and learning & $\begin{array}{l}\text { Discussion around delivery of remote teaching and learning; benefits } \\
\text { and challenges }\end{array}$ & $\begin{array}{l}17 \text { for teachers } \\
11 \text { for parents }\end{array}$ \\
\hline 3. Social and emotional impacts on students & $\begin{array}{l}\text { Concern for social and emotional development and well-being, both } \\
\text { short- and long-term }\end{array}$ & $\begin{array}{l}23 \text { for teachers } \\
11 \text { for parents }\end{array}$ \\
\hline 4. Academic impacts & Perceived short term and long-term impacts on academic outcomes & $\begin{array}{l}21 \text { for teachers } \\
11 \text { for parents }\end{array}$ \\
\hline 5. Impact on parents and families & Multiple impacts on families (both positive and negative) & $\begin{array}{l}23 \text { for teachers } \\
11 \text { for parents }\end{array}$ \\
\hline
\end{tabular}

\section{Results}

A total of five themes emerged from the parent and teacher datasets. A summary of the themes including a description and frequency for each theme can be found in Table 1 . The notation " $\mathrm{P}$ " is used to represent quotations from parent participants and ' $\mathrm{T}$ ' for teacher participants. Verbatim quotations are presented below; however, it is important to note that fillers (ums, uhs, etc.), stutters (in-in-in inconclusion), and ambient sounds were removed in the reporting of quotations.

\section{Theme 1: Equity Considerations}

A frequent theme that emerged across both stakeholder groups centred around equity considerations. Teachers and parents reported concerns with inequitable access to technology and missing essential resources. For example, this included connectivity issues as described by this parent, "Absolutely...we're a little bit [out] in the country, so we do have internet issues, and connectivity issues I would say more than anything else now." (P8). However, some families struggled with this more than others indicating that resources and access were not equal in the district. One parent stated, "it definitely puts a lot of things into perspective when you start looking at the inequities when it comes to access to stable internet" (P6). Teachers and parents also identified equity concerns related to the sharing of technology. More specifically, in some families technology was shared across multiple children, "Yeah, one of my kids [students] has 5 siblings and two of them are in high school, so my little guy is in grade 2 and his sister is in grade 1 and they never get on. They haven't been on yet. It's those times, they just say 'my brother he's using the Chromebook" (T7). Therefore, there were ongoing equity concerns related to technology as a result of the shift to remote learning.
Parents discussed the extent to which they were able to support their children with remote learning, which was often dependent on the amount of time that they could allocate. This parent described the amount of time required, "If I was working full time, I really don't know that I would be able to do it like this. I either would have had to take a leave of absence, or I don't think that I would have been able to get done as much as I'm doing now" (P4). This quotation highlights another inequity that moves beyond access to technology. This parent highlighted the time-consuming nature of remote learning. Some parents may be unable to support remote learning if they are working and unavailable to support their children while learning from home. Unsurprisingly many of the parents in the study were not teachers themselves and thus did not have formal teacher training. Therefore, many parents discussed the difficulties that they had with supporting remote learning given the lack of understanding of how to execute the lessons that were provided to their children. In contrast, one parent who was also a teacher shared their experiences, "I haven't taught kindergarten before but I know enough to know the questions to ask and how to navigate through tasks, whereas, I'm assuming for parents that have no background in teaching that it would be really challenging to try and navigate" (P11).

Participants were also concerned that remote learning would continue beyond the spring 2020 term and that this would have inequitable impacts for some students. Parents expressed deep concerns for the widening of learning gaps, given that students did not have equitable access or equal levels of support or resources available. One teacher suggested a way to address challenges with equitable access and learning was through the provision of home packages. More specifically, these home packages would provide families with supplies necessary to engage with the type of teaching and learning interactions that occur in the early primary grades, "If it is still remote learning, we will need go get supplies and ask our admin to order supplies for 
families: glue sticks, and scissors, and markers, and playdough and boxes of counters, and make sure every family has them. This way we can plan for the children knowing the materials they have. A family package will be needed" (T16). Transitioning from in-person to remote learning disadvantaged certain groups of students and families further while privileging others who had greater access to resources and supports. Findings from this research suggest that remote learning exacerbated inequitable access to resources and supports and may have widened learning gaps. Despite deep concern from teachers in regard to the potential long-term implications for some of their students (i.e., racialized students, students with exceptionalities, and students from low SES families), many of the teachers in this study differentiated their practices and provided additional supports in hopes to provide the support needed to offer equitable access to learning.

Despite the challenges associated with limited access to technology and allocation of resources, teachers and parents were cognizant of initiatives to improve access and equip students with the necessary resources. One way that teachers worked to accommodate a lack of access was by posting materials at the start of each week either on Sundays or Mondays. For example, one teacher explained, "Anything that we do that is live, is sort of above and beyond because we do have a number of students who do not have access to the computer during the day due to parents working, due to older siblings who have more pressing needs. You really could log-in at $8 \mathrm{am}$ on Monday, download everything for the week, and just do it on your own if that's the best fit. We try to make everything available asynchronous, do it at your own pace" (T9). Another way that teachers accommodated for differences in technology access was limiting the use of technology so that the learning was not dependent upon technology. For example, some students were still waiting on technology from the school board. This teacher explained, "A lot of my families, although the school board has given devices, a lot of them are still waiting or haven't accessed them yet, so I'm trying to make it as device-free as possible" (T8). Teachers also discussed the need to provide training to parents and families on how to use technology. Just giving them access to a tool is not enough. One teacher said that they would offer a workshop for families and elaborated, "It's made me think that maybe, if I were to return to this role again, I'm thinking maybe a workshop for my English Language Learners, like their families on, how to use technology, I know that sounds so simple, but so many of them don't know, they are not aware of certain things and to help them gain those skills I think would be so beneficial" (T21). This emergent theme captured the concerns that participants had regarding equitable access to learning opportunities for students. Participant responses focusing on equity considerations provided specific examples and suggestions for how to address learning gaps with differentiated teaching and flexible teaching practices.

\section{Theme 2: Synchronous vs. Asynchronous Teaching and Learning}

Remote teaching in Ontario was delivered both synchronously and asynchronously although the delivery method varied greatly across teachers. For example, some teachers opted for asynchronous delivery as this teacher described: "So at this point, we've been doing more asynchronous, especially with union directive, and yeah, a host of issues" (T23). Some teachers were considering transitioning to some synchronous delivery after starting with only asynchronous delivery as mentioned by this teacher "...right now [we] are talking about doing some video conferencing. We had been sort of uncertain about that, but it seems like, yeah, now it's okay, our principal is saying "it's okay, yep, go ahead and do it", we're just figuring out sort of that technology piece, how are we going to do that?" (T20).

Synchronous delivery included connecting with students in real-time whereas asynchronous opportunities consisted of posting all required materials online for students to work through without real-time interaction with their teacher or peers. Some teachers opted to deliver a blend of methods in order to meet the needs of their students with a hybrid of both synchronous and asynchronous teaching. Generally, parents and teachers reported that the delivery method was stipulated by the school board as mentioned by this parent, "the board had told them they are not allowed to do synchronous" (P7). However, parents did not necessarily agree with school boards mandating the type of delivery. Multiple parents expressed their desire for teachers to be given the flexibility to decide whether or not they wanted to teach synchronously or asynchronously. This parent explained, "I really wish that boards and [the] Ministry would let the teacher decide what is best" (P8). However, not all parents agreed with synchronous learning: "Personally, I have an issue with synchronous learning because I feel that there's a big equity and access issue that comes with that" (P6). In addition to equity concerns around synchronous learning, the same parent also emphasized the decreased flexibility for parents as a result. "All of a sudden school went from 8:00 to 9:00 in the morning, to 8:00 to $1: 30$, and it just eats up half of our day...again when it's streamlined like the way that we were doing it before, I feel like the kids were thriving better in that kind of environment" (P8). Despite the concerns expressed, there were also reported benefits of learning synchronously.

The benefits related to learning synchronously and inreal time with peers were frequently described in terms of social interactions. One teacher described the novel ways in which they built social connections remotely, stating that 
on a recent video call the teacher chose to play piano for the students. This experience brought about unique social connections, they shared "and they just clapped and clapped and I played you know, half a song and then they said 'keep going, keep going!' they just want that human connection, and they just want to have fun with you and see you as a person and, if you can't....rub their back and give them hugs then you have to do it in whatever way you can, and, last Friday it was playing piano for them" (T18). A few parents expressed their interests in synchronous learning as they want their children to have more social interactions even if that occurred behind a screen as mentioned by this parent, "It would be so wonderful if even there were like a Zoom meeting and the children could all see each other. My son would love that!" (P3). The teachers who delivered teaching synchronously also mentioned how much they appreciated being able to 'see' their students. One teacher detailed their weekly synchronous sessions: "I Google Meet every Friday at 10:30 with the students. This is going really well. We start the meetings by taking attendance. I say I'm going to write your name on this poster, then I can write their name in red. Just like we would do in the classroom. We do phonics songs, in French. We have them pick a letter, then we all did the phonics song for that letter. These are usually $45 \mathrm{~min}$ in length and 10-12 children log in each time. The parents are nearby, and I ask them to mute their mics and unmute them when their child wants to share. We went over this at the very beginning, so we had an expected practice for all" (T16). Despite the challenges of synchronous learning reported in this study, the teachers who met in real-time with their students felt that it was worthwhile. The findings from this theme highlight the benefits and challenges of synchronous and asynchronous teaching delivery models.

\section{Theme 3: Social and Emotional Impacts on Students}

Both parents and teachers discussed how the transition to remote learning had impacted students in kindergarten, grade 1, and grade 2. Participants expressed deep concerns over the negative social and emotional impacts of remote learning for students. Many teachers described how much their students missed their peers and how important social interactions are in the early primary grades. For example, one teacher shared, "...that's another thing we've been hearing from families, they're really missing seeing their friends" (T15). Similarly, a parent voiced concerns about interactions: "Socially it's important at 6 years old to be with kids your own age" (P3). Another parent shared similar concerns, "I think it would be really good for my child to still interact with their teachers and their peers, I think that's a piece that's really missing for them, for him specifically" (P7). Sometimes the concerns were greater for certain students, including those from lower socioeconomic backgrounds as this teacher reported, "Some haven't logged on, and I worry about the low SES friends and not being able to interact" (T16). Other times there were concerns for students who had no siblings at home as this teacher mentioned, "Some of the kids you can see are lonely. Especially children who don't have siblings. Some of the children you can see, they're shy when they're not normally shy, they're quiet when they're not normally quiet, a couple that are loud when they're not normally loud" (T9). The transition to remote learning also impacted the sense of community that had been established, "They miss human interaction and seeing their friends and their teachers and building that community" (T21). Another teacher emphasized the importance of interaction at the kindergarten level, "The social piece is also big, interaction with other children is so important in kindergarten. The playdates aren't happening- they are needed for well-being and overall development at this age." (T16). The repeated concern for a lack of social interaction was reported across the kindergarten to grade 2 levels.

Teachers also expressed concerns for some students who had limited social supports at home. More specifically, the teachers worried about students who did not have the safe, social, or positive home environments that they were used to in the classrooms. One teacher noted, "I know there are many children who unfortunately do not have the same loving and caring home environment as I am able to provide, and it is those children who benefit from school and childcare the most" (T5). A few teachers even discussed the potential long-term consequences that remote learning could have on students. This teacher elaborated, "Socially, though for children that come to school for food and for social interactions, this is another issue. We are more consistent parents for some children and therefore their experiences are drastically impacted, and this will have long-term implications socially and emotionally and academically. Also remember that many siblings are now taking care of their young siblings" (T10). This theme captured similar concerns from teachers and parents regarding lack of social interaction and emotional support unique to learning in the early primary grades.

\section{Theme 4: Academic Impacts}

Teachers and parents commonly discussed the academic impacts of remote learning in the early primary context. Some parents expressed concerns that the quality of teaching had diminished due to the transition to remote teaching and learning. One way that the diminished quality manifested was through a lack of differentiated instruction. For example, a parent mentioned their concern given that their child normally excelled in math and now, "she's bored out of her mind watching it. And so, watching that lesson for $30 \mathrm{~min}$ and then trying to do the worksheet, we've actually pulled 
out of the math days, I have her signed up on IXL because she can get way more math in way less time" (P8).

Parents highlighted several concerns regarding the academic impacts of remote teaching and learning, including their lack of professional training, their ability to engage their children, and their children's academic progress. In addition to reduced quality from teachers, the parents also expressed concerns for their own abilities to support their children learning, given that they do not have the professional training to support the academic learning of their children. One parent shared, "I worry about the quality of the teaching that [children are] getting from the parents and the frustration level I think is there so I think teachers obviously have the skill set to navigate difficult behaviours and just from experience and training and the parents ...you're not the teacher, so they don't see you as the teacher so it's hard to get them to think of doing things differently" (P1). Additionally, parents described how they struggled with having their children complete the work and engage while learning at home. For example, "If I force him to do the work. I would set him up to hate learning" (P3). The same parent expressed concern about impact on academic progress, "I do have to say that I am afraid of him losing a lot of the progress that he's made this year" (P3). However, in general, parents were not concerned with long-term academic consequences. One parent called this a little blip and elaborated, "I think he'll be okay academically and I'm sure that he'll be able to catch up for this little blip in his academic career" (P7). Further, another parent highlighted a potential benefit of remote learning, "I think it's going to give us the opportunity to show them independent learning and having questions and how to go about finding the answers on their own. I guess self-directed learning would be the big improvement" (P1). Despite the concerns, most parents reported that their children would overcome the negative academic effects of remote teaching and learning.

In comparison with parents, the teachers in this study expressed slightly different concerns related to academics. Teachers were worried that some parents were providing too much help and even completing the tasks for their children. Teachers discussed submissions with perfect spelling and grammar and work that was submitted at $2 \mathrm{am}$. This teacher explained, "It's like, some of my kids have been handing in work at 2 in the morning. And they're seven and eight, I know it's not them, and it comes back with proper grammar, and they're never forgetting periods...so, you can tell it's the parents" (T7). One strategy that they used to clarify their suspicions was to compare student work from before March to the work that was submitted during remote learning.

One teacher considered the implications of the additional help provided by parents in regard to assessment practices. "So yes, we are still assessing because we are asked to. But I find that my assessment is not true. Simply because I don't know if the kid is doing it on their own. Sometimes you can tell that the children's work is their work. But a lot of times you get assignments turned back and it's very clear that's not the child's work. Because you've seen how that child works at school, previously" (T12). Multiple teachers stated that schoolwork was not a priority for some parents. This teacher shared, "Academically a lot of the children have slowed down especially those children who may not be able to get the support they need to do the activities. I think that there is a high degree of anxiety in the community at large and doing your school work is not necessarily a priority for some" (T13).

Similarly to parents, a few teachers admitted that despite short-term concerns for students, they were not worried about long-term implications for the majority of their students. This teacher elaborated, "I don't really worry about gaps in learning for a lot of students, because I think they'll be okay" (P19). Similar to the findings from the equity theme discussed earlier, teachers discussed how the academic impacts may be greater for certain individuals. For example, one noted: "Grade 1 and 2 students in French Immersion and special needs students will mostly suffer long term effects because many are not getting the French language exposure that they need to thrive" (T13). Teachers also agreed with parents regarding the lack of differentiated instruction during remote learning and contrasted this with the inquiry pedagogical approach that is most common in the early primary grades. One teacher shared, "You know it's very inquiry based, my classroom is very much based on a student-centered approach where we, our learning is guided by what interests them, and how we can move learning forward through their interests... that's been very difficult because you know it's not a one stop shop, right? As opposed to being able to differentiate the learning for all the students in the class" (T17). Generally, when teachers and parents discussed the academic impacts of remote teaching and learning for early primary students, they were most likely to report negative effects.

\section{Theme 5: Impact on Parents and Families}

The final theme that emerged from the data focused on the impact of remote learning on parents and families. Participants were quick to provide multiple ways that parents and families had been impacted by the shift to learning at home. Teachers shared how they felt that parents and families were stressed and overwhelmed, "I know that some parents are stressed by it (remote learning)" (T2). Some teachers wondered if parents and families were stressed about the workload. This teacher explained, "But some are fine with that, you know if it's cooking or going on a walk, or in patterns, but some find it's like a checklist, a to-do list. And they're very stressed by that. And so I try to explain this is meant 
to be like exploratory, like you can do one or two...I don't know what your situation is"(T11). Having to take on the role of the teacher also added to the stress of families. This teacher elaborated, "I feel like parents are now having to take on that role as the teacher, and not really understanding that development of children in that sense, it's causing a lot of frustration in the home..." (T12). Another teacher mentioned similar concerns, "But there are a large number of parents who are juggling far too many roles and being very... I've had a lot of apologies: 'I'm really sorry I'm terrible at this' 'I'm really sorry I can't help my kid'. And I feel badly for them because they never signed up to be the teacher, they signed up to be the parent, and they're trying to fit themselves into a role and expecting themselves to be really good from day one" (T9). Teachers were clearly empathetic to the added stress that parents were experiencing.

Multiple teachers also talked about how parents may be caring for more than one child in their household adding to the demands: "There's one girl I'm thinking of who's in SK and she's [a] very strong student so we're not too concerned about her. And she has a brother in JK, and we know that her brother is not a strong student. So, her brother is not in our class he's in one of the others so we're wondering if that's part of it, that mom is dealing with the brother more" (T15). Three teachers also reported that they were concerned about the well-being of some parents. This teacher posited, "I have mental health concerns. The ones who the parents are struggling themselves and kids are picking up on the feelings from families. This is happening and the children are impacted" (T16). On a more positive note, teachers shared instances where parents had thanked them and expressed their appreciation. Simply put, “...I think parents value educators a lot more" (T14). It is clear that teachers were not only concerned for the well-being of their students, but they were also worried about the effect of added stress and workloads on parents and families more broadly.

Parents discussed how they had to transition in order to support their children. One parent detailed how they had come to accept the circumstances. "We're going to do what we can, and we're not going to stress that things aren't getting done completely and I think at the beginning we were ... we're going to try and get this done, maybe we'll have to do a couple things on the weekend to finish up and then I think as things progressed and you know every few weeks or a month there was a new announcement saying, it was extended. I kind of realized that we're in this for the long haul and we need to make this practical and sustainable" (P11). However, some parents admitted that they experienced greater stress than others, especially at the beginning as this parent shared, "I'm in a better place now, the whole learning from home ... But initially it was way too overwhelming" (P5). Parents also discussed struggles with having to schedule around remote learning and the impact of this added scheduling on their work, "We're all taking time away from our work to make sure that our kids are looked after" (P9). Another parent shared a challenge with scheduling, "... has been the great struggle with 4 kids, because all 4 have a synchronous class, ... so basically from 8:30 - 1:30 I'm juggling the kids in getting them on" (P8). Multiple parents raised concerns that they were not doing enough for their children as expressed here, "I'm constantly saying 'oh my gosh, I'm not doing enough for my child"' (P3). Parents were upfront about the challenges of filling so many roles at home including being the parent, the teacher, and a professional. One parent explained, "The challenges of course are time ... working from home, and trying to be professionals, and parents, and teachers at home, all three roles" (P5). Another parent reported similar concerns, "I feel like I'm only half doing my job as a parent and half doing my job as, as an employee so, you know?" (P7). Parents also shared the benefits of remote learning, such as getting to spend quality time with their child or developing their own understanding of what teachers do on a daily basis. One parent shared the insight gleaned, "But having her home has really sort of made me go 'oh wow, how did I miss these things' you know because we're given the insight into what our teachers are dealing with regularly. We're now on the path to getting some assessments done and all this other stuff" (P6). One parent was also happy about spending more time together and discussed further, "Certainly we're having a lot more quality time together and being able to, you know just try some things around the house that we haven't had the chance to do" (P7). Fortunately, parents and teachers were able to identify benefits despite the challenges that they experienced as a result of the transition to remote teaching and learning.

\section{Discussion and Conclusion}

The purpose of this study was twofold: (1) to capture the unique challenges and unanticipated successes associated with remote teaching and learning, and (2) to utilize findings to provide recommendations for remote learning as well as strategies for supporting in-person learning in the COVID19 era (and post COVID-19 era). The unique challenges and unanticipated successes associated with remote teaching and learning in the early primary context were highlighted in the results section (objective 1). A summary of the findings is presented below. Next, the findings are utilized to provide explicit recommendations for how to improve remote learning and offer strategies for supporting in-person learning in the COVID-19 era and post COVID-19 era (objective 2).

The thematic analysis revealed five themes: equity considerations, synchronous versus asynchronous teaching and learning, social and emotional impacts on students, academic impacts, and impacts on parents/families. Overall, 
the perspectives captured within these themes demonstrate that teachers and parents rose to the challenge to support children's learning amidst a global pandemic. In regard to equity considerations, teachers and families reported concerns with inequitable access to technology, connectivity issues, and missing essential resources/materials to accomplish the learning goals as they were set out. Although a lack of access to technology was a key concern in families where devices were shared across several family members, a larger concern was having the skills required to use the devices and software in meaningful ways. This finding is in keeping with the work of Dreeseni and colleagues (2020) who examined practices for equitable learning in 127 countries and suggested that access to content is only the first step to remote teaching and learning. Complimentary to the findings from our study, Dreeseni and colleagues highlight certain countries around the world who provided technical support and education for teachers, students, and parents to help them navigate the technology once they gained access. Similarly, parents discussed the extent to which they were able to support their children with remote learning which was dependent on the amount of time they could allocate as well as their knowledge of software and how to access the materials to share with their children remotely. This challenge is unique to early primary education where parents are required to take a leadership role in the delivery of instructional practices. Overall, transitioning to remote learning disadvantaged certain students and families and privileged others who had greater access to resources and supports. Findings from this research suggest that remote learning exacerbated inequitable access to resources and supports and may have widened learning gaps. Despite these concerns, participants provided specific examples and suggestions for how to address learning gaps with differentiated teaching and flexible teaching practices. The voices of teachers captured in this work are consistent with the recommendations suggested by educational leaders in the area of educational change in Canada. For example, Campbell et al. (2020) offer a proactive approach to safely re-opening schools that considers the possibility that individual schools will have to close again. Campbell et al., (2020) suggests that teachers use a range of formal and informal assessment strategies, differentiated instruction, and modified supports to meet the individual learning needs of students.

Participant discussions regarding equity concerns continued in conversations about synchronous and asynchronous methods of instruction. Findings revealed considerable disagreement amongst parents and teachers in regard to the benefits of synchronous and asynchronous learning. In some cases school boards mandated the use of one method over the other. However, parents did not necessarily agree with school boards mandating the type of delivery. Multiple parents expressed their desire for teachers to be given the flexibility to decide whether or not they wanted to teach synchronously or asynchronously. However, not all families agreed with synchronous learning, reporting concerns regarding the need for equitable access that comes with this delivery method. Many teaches opted to deliver a blend of methods in order to meet the needs of their students with a hybrid of both synchronous and asynchronous teaching. Despite the challenges of synchronous learning, the teachers who met in real-time with their students felt that it was worthwhile. The findings from this research highlight the benefits and challenges of synchronous and asynchronous teaching delivery models in early primary contexts. This work adds to the emerging literature on the benefits and challenges of using synchronous and asynchronous methods of teaching and learning (Mladenova et al., 2020; Ross \& DiSalvo, 2020

In discussing the transition to remote learning for children in kindergarten, grade 1 , and grade 2 , teachers and families voiced similar concerns for the negative social and emotional impact for students. Teachers and parents described the degree to which their students/children missed their peers and that this was particularly concerning given the focus on social skills in the early primary grades (2014b; Ontario Ministry of Education, 2014a, 2016). Teachers also expressed concerns for some students who had limited social supports at home. Overall, results indicated similar concerns from teachers and parents regarding lack of social interaction and emotional support unique to learning in the early primary grades.

In addition to social impacts, participants also discussed concerns regarding academic impacts for students. Families expressed concerns that the quality of teaching had diminished due to the transition to remote teaching and learning. One way that the diminished quality manifested was through a lack of differentiated instruction. Similarly, teachers discussed the lack of differentiated instruction during remote learning and contrasted this with the inquiry pedagogical approach that is most common in the early primary grades (2014b; Kirk \& Jay, 2018; Ontario Ministry of Education, 2014a, 2016; Trawick-Smith, \& Dziurgot, 2010). Parents also expressed concerns regarding a lack of ability to support their children's academic learning, given that they do not have the training required to offer quality learning opportunities for their children. Both parents and teachers admitted that despite shortterm concerns for student learning, they were not worried about long-term consequences for the majority of students. However, all participants discussed the potential lasting impacts for children who were already struggling with academic learning. Conversations focused on the widening of achievement gaps. The results of this study contextualize the findings of the rapid evidence assessment conducted by the Educating Endowment Fund (2020) within the context 
of early primary education. The rapid evidence assessment examined the existing research on the impact of school closures on academic achievement gaps more broadly and concluded with three key findings and implications: (1) school closures are likely to reverse progress made to narrow the gap in the last decade, (2) supporting effective remote learning will mitigate the extent to which the gap widens, and (3) sustained support will need to help disadvantaged pupils catch up (Education Endowment Fund, 2020, p. (4). Our research similarly highlights concerns for the reversing of progress made to narrow academic gaps, and suggests strategies for how to move forward to support equitable access to learning in the early primary years.

A common theme that emerged throughout the interviews was the impact of remote teaching and learning on parents and families. Teacher participants shared that parents and families were stressed and overwhelmed with the time that that was required of them to support their children's learning. Similarly, parents shared how the types of learning opportunities that are offered in the early primary grades require an adult or more expert peer to support with gaining access to the materials and executing the tasks. Parents reported feeling as if they were being spread thin and were unable to meet the needs of their careers, parenting, and teaching. Despite the many reported negative impacts of the additional roles for parents, they also expressed an appreciation for this extra time with their children. Parents shared stories of spending quality time with their children and also learning more about their interests and social and academic needs.

Although this research provided insight into teachers' and parents' experiences with remote teaching and learning, additional research is necessary. Given that teachers from the current study were interviewed at the beginning of the COVID-19 pandemic, it would be beneficial to interview teachers and parents following a longer time period with remote teaching and learning. This future research would offer the opportunity to capture the evolution of remote teaching practices. Additionally, there may be longstanding effects following the COVID-19 pandemic given that it has increased inequities and resulted in decreased social interactions. Thus, research should also examine the extent to which there are longitudinal effects on young children relating to their social, academic, and emotional development alongside their mental wellbeing. Similarly, there may also be longstanding effects on educators (including burnout) which will need to be examined further.

This research captured the voices of teachers and parents as they navigated uncharted territory and transitioned to remote teaching and learning. Building on the voices of the key stakeholders in this research, we offer ten explicit recommendations for how to improve remote teaching and learning as well as strategies for supporting in-person learning in the COVID-19 era and post COVID-19 era:

1 Dedicated training and professional development for teachers and parents on technology and software use.

2 More time to support the teaching and learning of appropriate technology use to all students in the early primary grades.

3 A need for an integrated approach to reaching children and families. This should involve working with community partners including childcare centres, medical professionals, family support programs, foodbanks, software and technology companies, libraries, and social workers, etc., to reach the needs of all families.

4 Encouraging a blend of synchronous and asynchronous teaching methods while being flexible to the individual needs of families. Synchronous time should allow for social interaction amongst students and smaller group interactions for academic learning.

5 Lessons need to be clearly explained to families and students. Families and students need to know where to access information on lessons, this information needs to be presented in the same format each week.

6 More individual instruction is needed to support the learning needs of all students. In addition to using synchronous time for social interaction we encourage the use of synchronous learning blocks in both ability- and flexible interest- based groups to provide additional time for tailored instruction.

7 Families need to be provided with home packs that include the resource and materials they need to support the types of activities that teachers are designing each week (i.e. glue, paper, scissors, etc.).

8 As students transition back to in person-learning, teachers will need to meet students where they are. There will be a need for both formal and informal assessments to be conducted to ensure that lessons are developmentally appropriate and meet the individual needs of their students.

9 Policy initiatives need to be put in place now, to support teachers in the event that learning is shifted online in the future. Despite many teachers currently working in person, there needs to be time dedicated to policy planning to ensure that teachers have the training required to support children and families with the ever changing education landscape. Current professional development initiatives should focus on improving remote teaching and learning practices.

10 Equity, diversity, and inclusion considerations need to be the focus of all short- and long-term decisions. 


\section{Strengths and Limitations}

Given that early primary education is not designed to be offered remotely, this study offers new insights on the challenges associated with remote teaching and learning in the early years. The main strengths of this study are encapsulated within the objectives of this work. This research captures the perspectives of key stakeholders (teachers and parents) on the unique challenges and unanticipated successes associated with remote teaching and learning while also providing explicit recommendations for remote learning and strategies for supporting in-person learning in the COVID-19 and post COVID-19 era. It is important to also address the limitations of this research. One consideration is that of social desirability: those who chose to participate and engage in the interview may be more likely to hold positive views overall. This research utilized qualitative interview data with teachers and parents in Ontario, Canada and thus was limited in its capacity to capture a large sample of geographically diverse participants. Larger samples of participants in geographically diverse locations are needed to determine the generalizability of this work. In-depth interviews conducted in this study allowed researchers to ascertain rich data which may not have otherwise been possible within a larger-scale survey-based research study.

\section{Conclusion}

This study sought to (1) capture the challenges and success of remote teaching and learning in a K-2 setting, and (2) to make recommendations for remote teaching and learning and the return to in-person learning, grounded in the research finding. The challenges and success of remote teaching and learning have been captured across five emergent themes: equity considerations, synchronous vs. asynchronous teaching and learning, social and emotional impacts on students, academic impacts, and impacts on parents and families. In consideration of these themes, the researchers made $10 \mathrm{rec}-$ ommendations for improving the practice of remote teaching and learning and for the eventual return to in-person learning. This research presents the unique challenges and unanticipated successes associated with remote teaching and learning in the early primary context. According to UNESCO (2020), COVID-19 is not only a global health pandemic, it has also resulted in a global crisis for education. Moving forward, this research can be used to support teachers, parents, and policymakers as efforts are made to address this global education crisis and mitigate the educational challenges that have resulted from the pandemic.

\section{Appendix A}

\section{Educator Interview}

1. What is your current role: ECE or Teacher? What grades are your currently teaching?

2. Overview of post-secondary education (highest level of education)?

3. Where did you complete your teacher/ECE training?

4. Years of teaching experience?

5. Years of teaching experience at the current grade level?

6. What supports have your school board and school put in place to support you with your teaching during the Learn at Home initiative? What resources/guidelines (number of hours) have been provided to you as you move your teaching to remote instruction?

7. How has your teaching been impacted by the move to remote learning? What has been the biggest challenge? Success?

8. What does effective remote learning look like for children in your class?

9. What does play and play-based learning look like in remote instruction?

10. Planning: How do you plan for remote learning? How is this different from the ways in which you planned previously?

11. Teaching and Learning: Describe what remote learning looks like for your students. Can you provide examples of a weekly schedule for your students?

12. Assessment: How do you assess learning that takes place remotely? What works? What isn't working? Provide Examples.

13. How has this move to remote learning impacted the learning of your students (academically and social)? What do you think will be the long and short-term effects of remote instruction on children?

14. How has it impacted parents? What is the role of parents during remote learning?

15. How do you think this move to remote learning will impact teaching and learning once we go back to classroom education?

16. If we are still offering remote instruction in the fall, what will teaching and learning look like then? (Difference between moving online without any planning to the comparison of having more time to prep for remote learning in the fall). What supports would you need to be successful in the fall?

17. Do you have any recommendations for other K-2 educators as they move their teaching online?

18. Is there anything else you would like to share? 


\section{Parent Interview}

1 How many adults and children are currently living in your household? What grades are your children in?

2 Can you describe what remote learning looks like for your child?

Can you describe what a week of learning looks like remotely for your child?

What (specific) types of activities/lessons have your children been given?

3 In your opinion how engaged are your child(ren) in this learning?

Very Engaged

Engaged

Somewhat engaged

Not Engaged

4 What best describes your child(ren)'s current involvement with their teacher(s) orschool:

Daily

More than once per week (less than daily)

Once per week

Less than once per week

As needed (available through email, phone, etc.)

No involvement

5 How has your child (kindergarten-grade 2) been impacted by the move to remotelearning? Successes? Challenges?

6 What do you think will be the long and short-term effects of remote instruction onchildren?

7 Do you feel as if your children's social, emotional, and cognitive needs are being metthrough remote learning?

Do you have any specific concerns for your children's learning?

8 What supports do you think your child(ren) will need when they return to school?

9 What is your role as a parent in supporting this remote delivery of teaching?

10 Does your family follow a structured daily routine?

Never

Rarely

Sometimes

Often

Always

Decline to respond

11 What are some of the best things about parenting right now?

12 What are some of the hardest things about parenting right now?

13 What are some things you wish you had that could help you with supporting yourchildren's learning right now?

14 Do you have any suggestions for how remote learning could be improved?
15 What supports would your children need if remote instruction continued into the fall?

16 Is there anything else you would like to add/share?

\section{References}

Alphonso, C. (2020). How different provinces have handled the school closures. The Globe and Mail. Retrieved from https://www.thegl obeandmail.com/canada/article-how-different-provinces-havehandled-the-school-closures/

Blair, C., McKinnon, R. D., \& Daneri, M. P. (2018). Effect of the tools of the mind in kindergarten program on children's social and emotional development. Early Childhood Research Quarterly, 43, 52-61. https://doi.org/10.1016/j.ecresq.2018.01.002

Campbell, C., Baumann, R., Kidder, A., \& Daniel, B. J. (2020). A gentle return to school: Go slow to go fast. Retrieved from https:// www.oise.utoronto.ca/lhae/UserFiles/File/Gentle_Reopening_of_ Ontario_Schools-2020.pdf

De Vries, E., Thomas, L., \& Warren, E. (2010). Teaching mathematics and play-based learning in an Indigenous early childhood setting: Early childhood teachers' perspectives. Playing with mathematics: Play in early childhood as a context for mathematical learning (pp. 719-722). Fremantle, Western Australia: MERGA Inc.

Dreeseni, T., Akseeri, S., Brossardi, M., Dewanii, P., Giraldo, J. P., Kamei, A., Mizunoya, S., \& Oritz, J. S. (2020). Promising practices for equitable remote learning: Emerging lessons from COVID-19 education responses in 127 countries (2020-10). Innoceti Research Brief. Retrieved from https://www.unicef-irc. org/publications/pdf/IRB\%202020-10.pdf

Education Endowment Foundation. (2020). Impact of school closures on the attainment gap: Rapid Evidence Assessment. Education Endowment Foundation.

Fahrurrozi, F., Murotono, M., Lestari, I., Sarifah, I., \& Sari Dewi, R. (2021). The usefulness of online learning on quality of education during COVID-19 pandemic: Evidence from the department of elementary school teacher education universitas Negeri Jakarta Indonesia. International Journal of Quality Research, 15(1), 107-125. https://doi.org/10.24874/IJQR15.01-06

Garbe, A., Ogurlu, U., Logan, N., \& Cook, P. (2020). COVID-19 and remote learning: Experiences of parents with children during the pandemic. American Journal of Qualitative Research, 4(3), 45-65. https://doi.org/10.29333/ajqr/8471

Ginsberg, H. P. (2006). Mathematical play and playful mathematics: A guide for early education. N D. Singer, R. M. Golinkoff, \& HirshPasek (Eds.), Play = learning: How play motivates and enhances children's cognitive and social-emotional growth (pp. 145-165). Oxford, EN: Oxford University Press. doi:https://doi.org/10.1093/ acprof:oso/9780195304381.003.0008

Ginsberg, H. P., Lee, J. S., \& Boyd, J. S. (2008). Math education for young children: What it is and how to promote it. Social Policy Report: Giving Child and Youth Development Knowledge Away, 22(1), 3-23.

Government of Canada. (2017). Statistics Canada: Calculation of instruction by jurisdiction. Retrieved from https://www150.statc an.gc.ca/n1/pub/81-604-x/2011001/tbl/tbl1-eng.htm

Government of Canada. (2020). Risk mitigation tool for children and youth settings operating during the COVID-19 pandemic. Retrieved from https://www.canada.ca/en/public-health/servi ces/diseases/2019-novel-coronavirus-infection/guidance-docum ents/covid-19-risk-mitigation-tool-child-youth-settings-opera ting-during-pandemic.html 
Government of Ontario. (2020a). Ontario helping students learn from the safety of their own home: Province launches first phased pe learn at home portal. Retrieved from https:// news.ontario.ca/en/release/56396/ontario-helping-stude nts-learn-from-the-safety-of-their-own-home

Government of Ontario. (2020b). Learn at home. Retrieved from https://www.ontario.ca/page/learn-at-home

Government of Ontario. (2020c). Ontario extends school and child case closures to fight spread of COVID-19: Province announces second phase of learn at home to support community learning. Retrieved from https://news.ontario.ca/en/ release/56529/ontario-extends-school-and-child-care-closu res-to-fight-spread-of-covid-19

Government of Ontario. (2020d). School closures extended to keep students, staff and families safe: Students will be able to complete school year. Retrieved from https://news.ontario.ca/en/ release/56776/school-closures-extended-to-keep-students-staffand-families-safe

Government of Ontario. (2020e). Ontario extended emergency orders during COVID-19 outbreak: Public health and safety remain top priorities. Retrieved from https://news.ontario.ca/en/relea se/57027/ontario-extending-emergency-orders-during-covid19-outbreak

Government of Ontario. (2020f). Ontario extends declaration of emergency to July 15: Province focuses on safe, gradual reopening of regions. Retrieved from https://news.ontario.ca/en/relea se/57362/ontario-extends-declaration-of-emergency-to-july-15

Government of Ontario. (2020g). Letters to Ontario's parents from the minister of education: March 31st, 2020. Retrieved from https://www.ontario.ca/page/letter-ontarios-parents-ministereducation\#section-5

Heagle, K., Timmons, K., Hargreaves, F., \& Pelletier, J. (2017). The social kindergartener: Comparing children's perspectives of full- and half-day kindergarten. Early Child Development and Care, 187(5-6), 223-241.

Hunting, R. (2010). Little people, big play and big mathematical ideas. In MERGA (Mathematics Education Reference Group of Australasia) 33, Shaping the future of mathematics education (pp. 725-730). 2010 Conference Report. Fremantle, Western Australia: MERGA Inc.

Kirk, G., \& Jay, J. (2018). Supporting kindergarten children's social and emotional development: Examining the synergetic role of environment, play, and relationships. Journal of Research in Childhood Education, 23(4), 472-485. https://doi.org/10.1080/ 02568543.2018 .1495671

Miruna, L. (2020). Digital media: Friend or foe? Preschool teachers' experiences on learning and teaching online. Journal of Pedagogy, 68(2), 203-221. https://doi.org/10.26755/RevPed/ 2020.2/203

Mladenova, T., Kalmukov, Y., \& Valova, I. (2020). Covid 19 - A major cause of digital transformation in education or just an evaluation test. TEM Journal, 9(3), 1163-1170. https://doi.org/10.18421/ TEM93-42

Moorhouse, B. L., \& Beaumont, A. M. (2020). Utilizing video conferencing software to teach young language learners in Hong Kong during the COVID-19 class suspensions. TESOL Journal, 11(3), 1-6. https://doi.org/10.1002/tesj.545

Ontario Ministry of Education. (2014a). Excerpts from "ELECT": Foundational knowledge from the 2007 publication of Early Learning for Every Child today: A framework for Ontario early childhood settings. Retrieved from http://www.edu.gov.on.ca/child care/ExcerptsFromELECT.pdf

Ontario Ministry of Education. (2014b). How does learning happen? Ontario's pedagogy for the early years. Retrieved from http:// www.edu.gov.on.ca/childcare/HowLearningHappens.pdf
Ontario Ministry of Education. (2016). The kindergarten program. Ottawa ON: Queen's Printer for Ontario. Retrieved from https:// files.ontario.ca/books/edu_the_kindergarten_program_english_ aoda_web_oct7.pdf

Patton, M. Q. (2002). Qualitative research \& evaluation methods. SAGE.

Piasta, S. B. (2016). Current understandings of what works to support the development of emergent literacy in early childhood classrooms. Child Development Perspectives, 10(4), 234-239. https://doi.org/10.1111/cdep.12188

Pinto, G., Bigozzi, L., Tarchi, C., Vezzani, C., \& Gamannossi, A. (2016). Predicting reading, spelling, and mathematical skills: A longitudinal study from kindergarten through first grade. Psychological Reports, 118(2), 413-440. https://doi.org/10.1177/ 0033294116633357

Purpura, D. J., Hume, L. E., Sims, D. M., \& Lonigan, C. J. (2011). Early literacy and early numeracy: The value of including early literacy skills in the prediction of numeracy development. Journal of Experimental Child Psychology, 110, 647-658. https:// doi.org/10.1016/j.jecp.2011.07.004

Ross, A., \& DiSalvo, M. (2020). Negotiating displacement, regaining community: The Harvard language center's response to the COVID-19 crisis. Foreign Language Annals, 53(2), 371-379. https://doi.org/10.1111/flan.12463

Pramling Samuelsson, I., Wagner, J. T., \& Eriksen Ødegaard, E. (2020). The coronavirus pandemic and lessons learned in preschools in Norway, Sweden and the United States: OMEP Policy Forum. International Journal of Early Childhood, 52(2), 129144. https://doi.org/10.1007/s13158-020-00267-3

Sangeeta, \& Tandon, U. (2020). Factors influencing adoption of online teaching by school teachers: A study during COVID-19 pandemic. Journal of Public Affairs. https://doi.org/10.1002/ pa. 2503

Schwartz, S. (2020). Early reading instruction takes a hit during COVID-19. Education Week, 39(35), 8-10

Thomas, D. R. (2006). A general inductive approach for analyzing qualitative evaluation data. American Journal of Evaluation, 27(2), 237-246. https://doi.org/10.1177/1098214005283748

Timmons, K. (2018). Educator expectations in Full-Day Kindergarten: Comparing the factors that contribute to the formation of early childhood educator and teacher expectations. Early Childhood Education Journal, 46(6), 613-628.

Timmons, K. (2019). Kindergarten expectations and outcomes: Understanding the influence of educator and child expectations on children's self-regulation, early reading and vocabulary outcomes. Journal of Research in Childhood Education, 33(3), 471-489.

Timmons, K., Cooper, A., Braund, H., \& Bozek, E. (2020). Examining the implementation and impact of the COVID-19 remote teaching initiative in Ontario early primary education contexts. Retrieved from https://static1.squarespace.com/static/5e7bd9fe0e bfc91090d87abc/t/5f4eb540f01a8727d196b418/1598994109562/ SUMMARY+REPORT+.pdf

Tobin, G. A., \& Begley, C. M. (2004). Methodological rigor within a qualitative framework. Journal of Advanced Nursing, 48, 388396. https://doi.org/10.1111/j.1365-2648.2004.03207

Trawick-Smith, J., \& Dziurgot, T. (2010). Untangling teacher-child play interactions: Do teacher education and experience influence "good-fit: responses to children's play? Journal of Early Childhood Teacher Education, 31(2), 106-128. https://doi.org/10.1080/ 10901021003781148

United Nations Educational, Scientific and Cultural Organization (UNESCO). (2020). COVID-19: A Global Crisis for Teaching and Learning. UNESCO.

Van Nuland, S., Mandzuk, D., \& Petrick, T. (2020). COVID-19 and its effects on teacher education in Ontario: a complex adaptive 
systems perspective. Journal of Education for Teaching, 46(4), 1-10. https://doi.org/10.1080/02607476.2020.1803050

Viner, R. M., Bonell, C., Drake, L., Jourdan, D., Davies, N., Baltag, V., Jerrim, J., Proimos, J., \& Darzi, A. (2021). Reopening schools during the COVID-19 pandemic: government must balance the uncertainty and risks of reopening schools against the clear harms associated with prolonged closure. Archives of Disease in Childhood, 106(2), 111-113. https://doi.org/10.1136/archdischi ld-2020-319963

Viner, R., Russell, M., Croker, S. J., Packer, H., Ward, J., Stansfield, C., Mytton, O., Bonell, C., \& Booy, R. (2020). School closure and management practices during coronavirus outbreaks including COVID-19: A rapid systemic review. Lancet Child Adolescent Health, 4, 397-404. https://doi.org/10.1016/S2352-4642(20) 30095-X

Wang, G., Zhang, Y., Zhao, J., Shang, J., \& Jiang, F. (2020). Mitigating the effects of home confinement on children during the COVID-19 outbreak. Lancet, 395, 945-947. https://doi.org/10.1016/S01406736(20)30547-X

Wilder-Smith, A., \& Freedmann, D. O. (2020). Isolation, quarantine, social distancing and community containment: Pivotal role for old-style public health measures in the novel coronavirus
(2019-nCoV) outbreak. Journal of Travel Medicine, 27(2), 1-4. https://doi.org/10.1093/jtm/taaa020

World Food Program. (2020). Global monitoring of school meals during COVID-19 school closures. Retrieved from https://cdn.wfp. org/2020/school-feeding-map/index.html

Yamamura, E., \& Tsustsui, Y. (2021). The impact of closing schools on working from home during the COVID-19 pandemic: evidence using panel data from Japan. Review of Economics of the Household, 19(1), 41-60. https://doi.org/10.1007/s11150-020-09536-5

Yi, Y., \& Jang, J. (2020). Envisioning possibilities amid the COVID-19 pandemic: implications from english language teaching in South Korea. TOSEL Journal, 11(3), 1-5. https://doi.org/10.1002/tesj. 543

Publisher's Note Springer Nature remains neutral with regard to jurisdictional claims in published maps and institutional affiliations. 